\title{
$\nabla$
}

\section{Ultraviolet index: a light in atopic dermatitis and vitamin D research?*}

\author{
Kleyton de Carvalho Mesquita ${ }^{1,2,3}$ \\ Izelda Maria Carvalho Costa $^{1}$
}

\author{
Ana Carolina de Souza Machado Igreja ${ }^{1,3}$
}

DOI: http:/ /dx.doi.org/10.1590/abd1806-4841.20164337

\begin{abstract}
BACKGROUND: The role played by vitamin D in atopic dermatitis is controversial and has been the focus of many studies. The ultraviolet index has not been considered in this type of research.

OвJEctives: The objectives of the study were to assess 25-hydroxy vitamin D [25(OH)D] serum level in atopic dermatitis patients and control group, to investigate the association between atopic dermatitis clinical severity (using the SCORing Atopic Dermatitis index - SCORAD) and 25(OH)D serum levels, and to evaluate the independent predictors, including Ultraviolet index, SCORAD and 25(OH)D.

Methods: We conducted a cross-sectional study of 106 atopic dermatitis patients. A control group was matched with a subsample of 54 participants with atopic dermatitis. SCORAD index, laboratory tests, and local Ultraviolet index were assessed.

REsUlTs: The atopic dermatitis patients had serum 25(OH)D levels and mean UVI significantly higher than the control group. Immunoglobulin E and Ultraviolet index were associated with the SCORAD index. Skin type, age and Ultraviolet index were independent predictors of $25(\mathrm{OH}) \mathrm{D}$.

Conclusions: Although statistically significant, the different levels of $25(\mathrm{OH}) \mathrm{D}$ between the paired groups may be attributed to the higher mean Ultraviolet index in atopic dermatitis patients. Since Ultraviolet index is an independent predictor of SCORAD index and of $25(\mathrm{OH}) \mathrm{D}$ level, it may work as a confounding factor in studies involving atopic dermatitis and $25(\mathrm{OH}) \mathrm{D}$ and must be considered in this kind of research.
\end{abstract}

Keywords: Dermatitis, atopic; Ultraviolet rays; Vitamin D

\section{INTRODUCTION}

Atopic dermatitis (AD) is a prevalent disease in childhood. Its etiopathogenesis is complex and is not completely understood. ${ }^{1}$ Two major characteristics of $\mathrm{AD}$ are skin barrier dysfunction and immune dysregulation. $^{2}$

Vitamin D is a fat-soluble vitamin synthesized mainly in the skin when exposed to ultraviolet B (UVB). ${ }^{3}$ The biological actions of vitamin $\mathrm{D}$ have been widely studied in recent decades. Its extraskeletal actions are now better understood, and vitamin D has been linked to a broad range of autoimmune, neoplastic, inflammatory, degenerative, metabolic and allergic diseases. ${ }^{4}$ In this context, clinical trials have failed to demonstrate a causal relationship.

Given the immunomodulatory role of vitamin $\mathrm{D}$ combined with its action in skin barrier formation and recovery, reducing transepidermal water loss and stimulating the production of antimicrobial peptides (AMP) by keratinocytes, macrophages, and neutrophils, it is reasonable to suppose that there is a link between the actions of vitamin D and the etiopathogenesis of AD., ${ }^{3,5-9}$ However, findings related to the association between vitamin $\mathrm{D}$ and atopic diseases are scarce and conflicting. Some researchers have demonstrated the association between $\mathrm{AD}$ and hypovitaminosis D or low vitamin D intake, whereas other studies have shown higher chance of $\mathrm{AD}$ with high vitamin $\mathrm{D}$ intake. ${ }^{10-14} \mathrm{~A}$ negative association between vitamin $\mathrm{D}$ and $\mathrm{AD}$ clinical severity has been reported but not confirmed in other studies. ${ }^{15-17}$ Recently, clinical improvement of the disease after vitamin $\mathrm{D}$ supplementation has been demonstrated. ${ }^{16,18,19}$

\footnotetext{
Received on 04.01.2015.

Approved by the Advisory Board and accepted for publication on 15.03.2015.

Financial Support: None.

Conflict of Interest: None.

Universidade de Brasília (UnB) - Brasilia (DF), Brazil.

Secretaria de Estado de Saúde do Distrito Federal - SES (DF) - Brasilia (DF), Brazil

Private clinic - Brasilia (DF), Brazil.

C2016 by Anais Brasileiros de Dermatologia
}

Work performed at the Hospital Universitário de Brasília - Universidade de Brasília (HUB-UnB) - Brasilia (DF), Brazil. 
There is no consensus regarding optimal serum levels of 25-hydroxy vitamin D [25(OH)D], the metabolite used to determine the overall status of vitamin $\mathrm{D}$, or the time of its storage after the 25-hydroxylation of vitamin D in the liver. The Endocrine Society established that the adequate level of vitamin $\mathrm{D}$ is between 30 and $100 \mathrm{ng} / \mathrm{ml}$, the insufficient level is between 20 and $29.9 \mathrm{ng} / \mathrm{ml}$, and deficient level is $<20 \mathrm{ng} / \mathrm{ml} .^{20}$

Ultraviolet (UV) radiation exerts immunosuppressive effects in $\mathrm{AD}$ patients and has been used successfully in the treatment of $\mathrm{AD}$, in methods like phototherapy or heliotherapy. ${ }^{21}$ However, overexposure to UV radiation from the sun and artificial UV radiation sources is a public health concern. UV radiation predisposes to skin cancer development and eye damage. In 1995, in order to raise public awareness about the excessive exposure to UV and the need to adopt protective measures, the World Health Organization (WHO), together with several partner organizations, developed the Global Solar Ultraviolet Index (UVI). The UVI is a measurement of UV radiation levels reaching the Earth's surface. The WHO defines five UVI exposure categories: low, moderate, high, very high, and extreme. ${ }^{22,23} \mathrm{UVI}$ is easily obtained from meteorological centers. Nevertheless, it has not been considered in research involving the association between $\mathrm{AD}$ and $25(\mathrm{OH}) \mathrm{D}$ and its influence is unknown, as seen in the published results.

The main objectives of the present study were to investigate the prevalence of hypovitaminosis $\mathrm{D}$ in patients with $\mathrm{AD}$ and a matched control group, the association of AD clinical severity with $25(\mathrm{OH}) \mathrm{D}$ levels, and to analyze the independent predictors of $25(\mathrm{OH})$ $\mathrm{D}$ and $\mathrm{AD}$ clinical severity, including UVI among the tested variables.

\section{METHODS}

This cross-sectional study used a convenience sample of the pediatric dermatology outpatient clinic of the Hospital Universitário de Brasilia, located in Brasilia, Brazil (latitude $15^{\circ} 46^{\prime}$ S, longitude $47^{\circ} 55^{\prime} \mathrm{W}$ ). Data were collected by a single interviewer. The study was approved by the Research Ethics Committee at the School of Medicine of the University of Brasilia.

Inclusion criteria for the AD group were: age between 0 and 18 years old and diagnosis of AD according to Hanifin \& Rajka criteria. ${ }^{24}$ The use of emollients, topical corticosteroids and oral antihistamines was allowed. Exclusion criteria were: systemic diseases; vitamin supplementation in the last 6 months; use of topical calcineurin inhibitors or oral corticosteroids in the past 4 weeks; phototherapy; use of anticonvulsants, anticoagulants or antifungal drugs; and dermatoses or therapies that lead to reduced or increased sun exposure.
Inclusion criteria for the control group were age between 0 and 18 years old and adequate characteristics for the matching criteria. The control group patients were matched (1:1) with a subsample of $54 \mathrm{AD}$ patients, selected according to the chronological order in which these patients entered the study. The control case was matched to an index case according to gender (same gender); age (same age \pm 2 years); body mass index, BMI (same BMI $\pm 2 \mathrm{~kg} / \mathrm{m}^{2}$ ); and Fitzpatrick skin type scale (same skin type \pm 1 ). The controls who met the same exclusion criteria as the cases and the individuals with any kind of atopy, psoriasis, and rosacea were excluded. The patients of the AD and control groups were selected from the same pediatric dermatology outpatient clinic.

The present study was conducted from November 2012 to October 2013. AD severity was assessed using the total SCORing Atopic Dermatitis (SCORAD) index. ${ }^{25}$ The following data were collected from AD patients: age, gender, skin type, BMI, other personal atopy [asthma or allergic rhinitis (AR)], familial atopy, age of onset of AD symptoms, SCORAD index, $25(\mathrm{OH}) \mathrm{D}$, immunoglobulin $\mathrm{E}(\mathrm{IgE})$, complete blood count, and stool test. The data needed for matching and $25(\mathrm{OH}) \mathrm{D}$ were collected from the control group. We calculated the mean of local maximum UVI in the 30 days prior to clinical evaluation individually in $\mathrm{AD}$ and control patients (Figure 1).

All cases and controls had their serum $25(\mathrm{OH})$ $\mathrm{D}$ levels measured using the immuno-chemiluminescence method - LIAISON XL platform (Diasorin, Sallugia, Italy). The $25(\mathrm{OH}) \mathrm{D}$ status was determined according to the reference values adopted by The

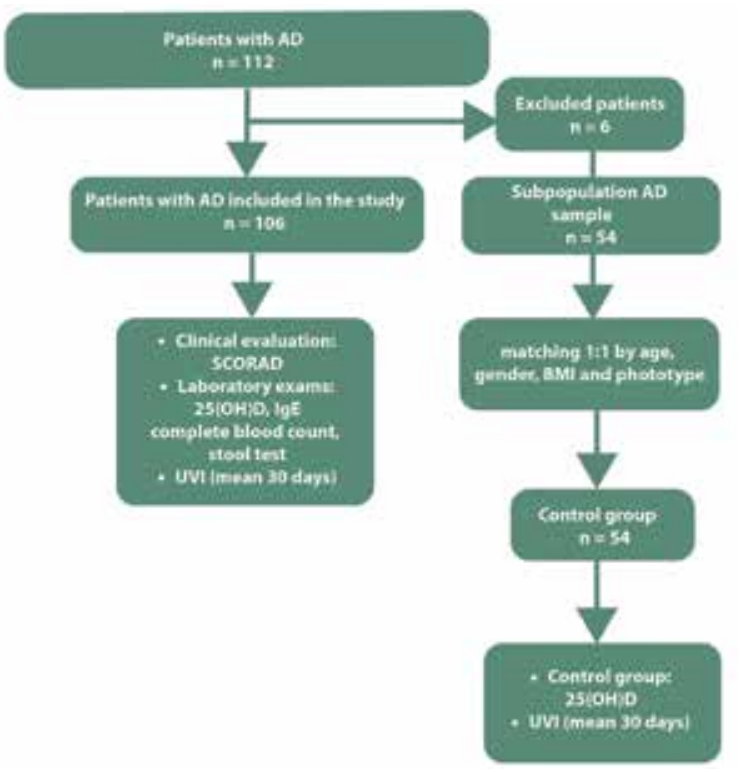

FIGURE 1: Inclusion flowchart (patients with AD and controls) 
Endocrine Society. ${ }^{20}$ Total serum IgE was measured by immunonephelometry using the BN II and BN ProSpec systems (Siemens, Marburg, Germany). Complete blood counts were performed using Cell-Dyn Ruby Abbott (Abbott Laboratories, Abbott Park, Illinois USA), and the stool tests were conducted using the spontaneous sedimentation method. Local UVI was obtained daily via the Brazilian Center for Weather Forecasting and Climate Studies site (available at http:/ / satelite.cptec.inpe.br/uv/). The UVI was estimated using a mathematical-physical model, which describes transfer of UV radiation emitted by the sun in the Earth's atmosphere.

Data were statistically analyzed using SAS 9.3 (SAS Institute, Cary, NC, USA). The associations included quantitative and qualitative variables. Associations were considered to be statistically significant when the $p$-value was $<0.05$. Unless otherwise specified, we used the Pearson linear correlation coefficient to analyze two quantitative variables and the Kruskall-Wallis test for qualitative variables. Paired Student's $t$ test was used to compare $25(\mathrm{OH}) \mathrm{D}$ and UVI between the pairs of the matched groups. Multivariate analysis was performed using multiple linear regression.

\section{RESULTS}

Our sample consisted of 106 AD patients and 54 control group patients (Table 1). The prevalence of $25(\mathrm{OH}) \mathrm{D}$ insufficiency was $41.51 \%$ and of deficiency $16.04 \%$, resulting in a $57.55 \%$ prevalence of hypovitaminosis $\mathrm{D}$ in the AD group. The local UVI in the period of completion of the study ranged from high to extreme levels (Figure 2). The stool tests did not detect presence of helminths.

Hypovitaminosis D was present in $77.78 \%$ of the control group (Table 2). The $54 \mathrm{AD}$ patients had mean $25(\mathrm{OH}) \mathrm{D}$ significantly higher than those in the control group (mean difference $3.4 \mathrm{ng} / \mathrm{ml}, \mathrm{t}=2.45, \mathrm{p}=0.018$ ). The marginal homogeneity test was performed to compare the $25(\mathrm{OH}) \mathrm{D}$ status between the groups. The hypothesis of marginal equality could not be rejected ( $p$ $=0.089$ ); therefore, the proportion of patients with deficient, insufficient and adequate $25(\mathrm{OH}) \mathrm{D}$ levels did not differ between the groups. Index patients had mean UVI significantly higher than the control group (mean difference 2.54 index points, $t=6.10, \mathrm{p}<0.001$ ).

The quantitative analysis of variables using the SCORAD index and $25(\mathrm{OH}) \mathrm{D}$ level was not statistically significant ( $\mathrm{n}=106, \mathrm{r}=0.342, \mathrm{p}=0.727$ ) (Figure 3 ). Multiple linear regression analysis $\left(\mathrm{r}^{2}=0.230\right)$ showed that IgE and UVI were predictors significantly associated with SCORAD ( $\beta=0.002,95 \%$ CI [0.001, 0.004], $p$ $<0.001$ and $\beta=-1.35,95 \%$ CI [-2.357, -0.352], $p=0.009$, respectively). The associations between SCORAD and the other variables [age, gender, Fitzpatrick skin type,
TABLE 1: Clinical, epidemiological, and laboratory characteristics of the $\mathrm{AD}$ group

\begin{tabular}{|c|c|}
\hline & $\begin{array}{l}\text { Subjects with AD } \\
(\mathrm{n}=106)\end{array}$ \\
\hline Age (years) & $8.2 \pm 4.0$ \\
\hline \multicolumn{2}{|l|}{ Gender } \\
\hline Male & $38(35.85 \%)$ \\
\hline Female & $68(64.15 \%)$ \\
\hline \multicolumn{2}{|l|}{ Fitzpatrick skin type } \\
\hline II & $7(6.60 \%)$ \\
\hline III & $30(28.30 \%)$ \\
\hline IV & $65(61.32 \%)$ \\
\hline $\mathrm{V}$ & $4(37.78 \%)$ \\
\hline BMI (kg/m2) & $17.8 \pm 3.7$ \\
\hline \multicolumn{2}{|l|}{ Asthma or AR } \\
\hline Yes & $60(56.60 \%)$ \\
\hline No & $46(43.40 \%)$ \\
\hline \multicolumn{2}{|l|}{ Familial history of atopy } \\
\hline Yes & $72(67.92 \%)$ \\
\hline No & $34(32.08 \%)$ \\
\hline Age of onset (years) & $2.1 \pm 2.8$ \\
\hline SCORAD index & $28.3 \pm 15.3$ \\
\hline Mild AD & $49(46.23 \%)$ \\
\hline Moderate AD & $48(45.28 \%)$ \\
\hline Severe AD & $9(8.49 \%)$ \\
\hline 25(OH)D (ng/ml) & $29.0 \pm 9.7$ \\
\hline Sufficiency & $45(42.45 \%)$ \\
\hline Insufficiency & $44(41.51 \%)$ \\
\hline Deficiency & $17(16.04 \%)$ \\
\hline Total IgE (IU/ml) & $1242.8 \pm 2297.7$ \\
\hline Eosinophils (\%) & $7.7 \% \pm 5.0$ \\
\hline UVI (mean of 30 days) & $11.65 \pm 2.81$ \\
\hline
\end{tabular}

Values expressed as mean \pm standard deviation or $\mathrm{n}(\%)$

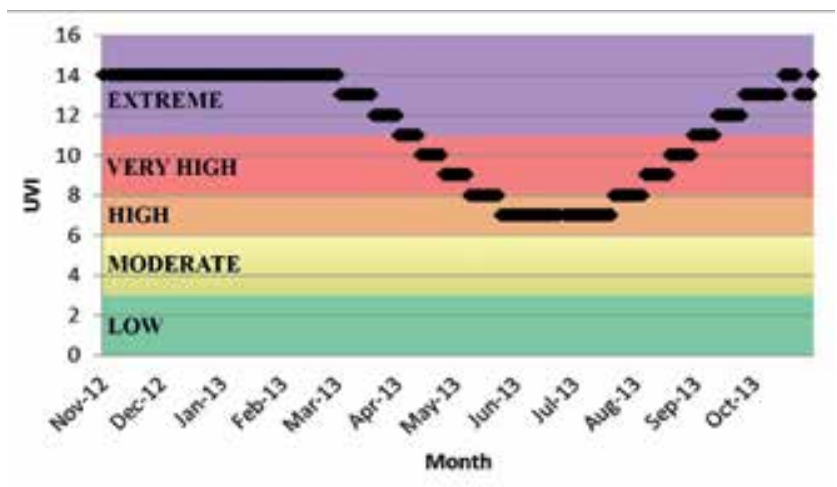

FIGURE 2: Maximum daily UVI in the city of Brasilia during the study 
TABLE 2: Epidemiological and laboratory characteristics of AD subgroup and control group

\begin{tabular}{lll}
\hline & $\begin{array}{l}\text { AD subgroup } \\
(\mathrm{n}=54)\end{array}$ & $\begin{array}{l}\text { Control group } \\
(\mathrm{n}=54)\end{array}$ \\
\hline $\begin{array}{l}\text { Age (years) } \\
\text { Gender }\end{array}$ & $9.1 \pm 4.1$ & $9.0 \pm 4.3$ \\
$\quad$ Male & $22(40.74 \%)$ & $22(40.74 \%)$ \\
$\quad$ Female & $32(59.26 \%)$ & $32(59.26 \%)$ \\
Fitzpatrick skin type & & \\
$\quad$ II & $1(1.85 \%)$ & $5(9.26 \%)$ \\
III & $17(31.48 \%)$ & $9(16.67 \%)$ \\
IV & $35(64.82 \%)$ & $39(72.22 \%)$ \\
V & $1(1.85 \%)$ & $1(1.85 \%)$ \\
BMI (kg/m2) & $17.7 \pm 2.6$ & $17.8 \pm 2.5$ \\
25(OH)D (ng/ml) & $29.0 \pm 8.8$ & $25.6 \pm 7$ \\
Sufficiency & $23(42.59 \%)$ & $12(22.22 \%)$ \\
Insufficiency & $21(38.89 \%)$ & $33(61.11 \%)$ \\
Deficiency & $10(18.52 \%)$ & $9(16.67 \%)$ \\
UVI (mean of 30 days) & $12.85 \pm 2.09$ & $10.31 \pm 2.54$ \\
\hline
\end{tabular}

Values expressed as mean \pm standard deviation or $\mathrm{n}(\%)$

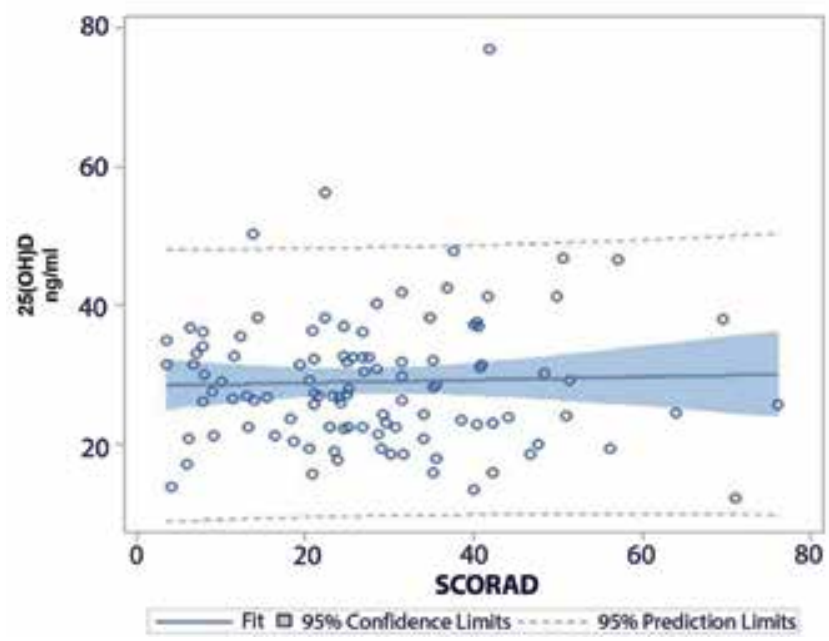

Figure 3: Correlation between 25(OH)D and SCORAD

BMI, asthma or AR (yes or no), familial history of atopy (yes or no), age of onset of $\mathrm{AD}$ and eosinophils] were not statistically significant $(p>0.05)$.

Multiple linear regression analysis $\left(\mathrm{r}^{2}=0.188\right)$ showed that the variables skin type, age and UVI were predictors significantly associated with $25(\mathrm{OH}) \mathrm{D}$. Patients with skin type II and III showed mean $25(\mathrm{OH}) \mathrm{D}$ level of $5.4 \mathrm{ng} / \mathrm{ml}$ higher than patients with skin type IV and V $(\beta=6.102,95 \%$ CI [2.116, 10.088], $p=0.003)$. Older patients were associated with lower $25(\mathrm{OH})$ D levels than younger patients $(\beta=-0.570,95 \% \mathrm{CI}$ $[-1.044,-0.096], p=0.019)$. Furthermore, the higher the
UVI, the greater the levels of $25(\mathrm{OH}) \mathrm{D}(\beta=0.739,95 \%$ CI [0.086, 1.391], $\mathrm{p}=0.027)$. The associations between 25(OH)D levels and the other variables [gender, BMI, asthma or AR (yes or no), familial history of atopy (yes or no), total IgE and eosinophils] were not statistically significant $(\mathrm{p}>0.05)$. There was no significant seasonal effect on either SCORAD or 25(OH)D level.

\section{DISCUSSION}

The prevalence of hypovitaminosis $\mathrm{D}$ was $57.55 \%$ in the AD group. This prevalence rate is similar to that reported by Weng et al. ${ }^{26}(55 \%)$ and Peters et al. ${ }^{27}(60 \%)$ in adolescents. This prevalence was higher in the control group, affecting $77.78 \%$ of these patients. Such high prevalence rates are a reason for concern, since maximizing the peak of bone mass during adolescence and early adulthood is considered to be the best protection against age-related bone loss and late risk of osteoporosis. ${ }^{28}$ Although this study was conducted in a city with high UVI, ranging from high to extreme, this was not enough to prevent the high prevalence of $25(\mathrm{OH}) \mathrm{D}$ insufficiency. Other authors have also found low levels of $25(\mathrm{OH}) \mathrm{D}$ in healthy individuals living in sunny regions. ${ }^{29}$

We demonstrated that $\mathrm{AD}$ subgroup patients had $25(\mathrm{OH}) \mathrm{D}$ levels higher than matched controls. However, $25(\mathrm{OH}) \mathrm{D}$ status was not statistically different between the groups. Because small variations in the serum $25(\mathrm{OH}) \mathrm{D}$ level may not be clinically significant, the association between categorical variables seems to be more appropriate. Although some studies suggest a positive association between atopy and vitamin $\mathrm{D}$, we believe that the higher level of $25(\mathrm{OH}) \mathrm{D}$ in $\mathrm{AD}$ patients is linked to the higher UVI in this group, as demonstrated by the paired analysis in our sample. 14,30,31 We found no statistically significant association between $25(\mathrm{OH}) \mathrm{D}$ levels and AD clinical severity, which is in agreement with recent publications. . $^{16,17,32}$

In terms of independent variables associated with AD severity, the association with IgE is well known and has been reported by several other studies. ${ }^{33}$ Despite its inclusion among the diagnostic criteria of $\mathrm{AD}$, it has not been established whether IgE sensitization is useful to the management and research of AD.

Age, skin type and UVI were significantly associated with serum $25(\mathrm{OH}) \mathrm{D}$ levels, according to the multivariate analysis. The older the patient, the lower the serum $25(\mathrm{OH}) \mathrm{D}$ level. The reason for this association in a young population is not clear, although it has been previously reported. ${ }^{26}$ We agree with the authors who suggest that older children and adolescents may spend less time playing outdoors or may have a reduced oral supplementation of vitamin D. ${ }^{17,26}$ The reduction in the $25(\mathrm{OH}) \mathrm{D}$ levels in higher skin types is expected because melanin competes for UVB photons. Considering the 
physiology of vitamin $\mathrm{D}$, the positive association between UVI and $25(\mathrm{OH}) \mathrm{D}$ is expected, since UVB radiation promotes the photolysis of 7-dehydrocholesterol and initiates the synthesis of vitamin D. ${ }^{34}$

The association between UVI and SCORAD was expected, even though UVI has been poorly considered in $\mathrm{AD}$ researches. Once the UVB radiation is needed for the physiological synthesis of vitamin $\mathrm{D}$ and UV radiation simultaneously exerts immunosuppressive effects in $\mathrm{AD}$ patients and reduces the clinical severity of $\mathrm{AD}$, including UVI as an independent variable is of the utmost importance in the context of $\mathrm{AD}$ and $25(\mathrm{OH}) \mathrm{D}^{35-37}$

We found no influence of the season on AD severity and $25(\mathrm{OH}) \mathrm{D}$ levels, maybe because the study was conducted in a very sunny city throughout the year, with low variation of its maximum UVI level. Most studies associate seasons to atopic diseases without considering the UVI. However, we consider that environmental influence on $\mathrm{AD}$ and $25(\mathrm{OH}) \mathrm{D}$ may be best measured with the UVI, at least in areas with poorly defined seasons. The association between UVI and $\mathrm{AD}$ is a recent theme and there are few published studies. Silverberg et al. demonstrated lower prevalence of AD in U.S. states with the highest UVI. ${ }^{38}$ The same way, studies associate UVI to other diseases (e.g., hay fever and prostate cancer) in a populational basis. ${ }^{39,40} \mathrm{We}$ could not find studies that assessed UVI individually.

Although created in order to raise awareness of the need for sun protection, we consider that the importance of UVI is beyond the scope of its creation and we advocate its use in research involving diseases that may be influenced by UV radiation, such as AD and psoriasis. UVI represents an important confounding factor and may distort results, especially in places with large variation of this index. In this context, considering UVI is highly important when subjects are compared.

It must be emphasized that the maximum daily UVI score does not represent the actual daily sun exposure of the participants. We did not measure time and duration of UV exposure in volunteers. Therefore, the variable UVI cannot be considered the only predictor of UV exposure. The ideal method for accurate and reliable measure of individual UV exposure would be personal UV dosimeters. Personal UV dosimeters are able to provide a dynamic and objective measurement of cumulative UV exposure, since its result is determined by the daily variations of UV exposure and by environmental conditions. The most widely used chemical dosimeters are polysulfone or polyphenylene oxide. Nowadays electronic devices are also available.

We considered a period of 30 days prior to clinical evaluation to calculate mean UVI individually. However, there is no consensus about the amount of UV exposure needed to maintain vitamin $\mathrm{D}$ levels. We established this period considering the half-life of $25(\mathrm{OH})$
D (about two to three weeks), the related improvement of AD severity after 4 weeks of climatotherapy, and variation of individual habits of sun exposure, trying to reach intentional and non-intentional sun exposure periods. ${ }^{34,41}$ The production and degradation of $25(\mathrm{OH})$ $\mathrm{D}$ is a continuous process. Establishing the ideal period to measure UV effects both in $25(\mathrm{OH}) \mathrm{D}$ production and immunosuppression on an individual basis is a hard task in clinical research and needs to be better evaluated in prospective studies. To the best of our knowledge, this is the first study to consider UVI in research associating $25(\mathrm{OH}) \mathrm{D}$ and $\mathrm{AD}$. Once mean UVI is significantly associated with $25(\mathrm{OH}) \mathrm{D}$ and SCORAD, the 30 days period may be a starting point to evaluate this issue.

This study was strictly controlled by the researchers, thus minimizing measurement biases. All tests were performed at the same laboratories, therefore ensuring technical uniformity. This strategy is of paramount importance for the measurement of $25(\mathrm{OH}) \mathrm{D}$ levels because of the well-known inter assay variation. ${ }^{34}$ Our study limitations include the lack of evaluation of the following variables: sun exposure, dietary vitamin $\mathrm{D}$ intake, clothing, sunscreen use, albumin, serum calcium levels, magnesium and phosphorus, BMD, markers of bone turnover, and renal function. Furthermore, although largely used, the chemiluminescence method used to measure $25(\mathrm{OH}) \mathrm{D}$ is not the most accurate and has wide variability. ${ }^{34,42}$ Since this was a cross-sectional study, only a single point in time was evaluated. The level of $25(\mathrm{OH}) \mathrm{D}$ may vary greatly over short time intervals, depending on vitamin D intake and sun exposure. ${ }^{43}$

\section{CONCLUSION}

In conclusion, we found higher levels of $25(\mathrm{OH})$ $\mathrm{D}$ in $\mathrm{AD}$ patients than in paired controls, probably because of the higher mean UVI of those patients. There was no association between SCORAD and 25(OH)D. The role of vitamin $\mathrm{D}$ in atopic diseases is controversial and continues to be investigated worldwide. The extent of its impact on the immune system and specifically on allergic diseases has yet to be elucidated. We demonstrated the relevance of UVI as a predictor of $25(\mathrm{OH}) \mathrm{D}$ and of SCORAD, even though we had not considered solar exposure of participants. UVI can be easily obtained and should be included in studies involving $25(\mathrm{OH}) \mathrm{D}$ and diseases influenced by UV because it may represent a confounding factor and distort results. The use of UVI individually in clinical research may shed some light and eliminate any shadow of doubt in $\mathrm{AD}$ and vitamin $\mathrm{D}$ research.]

\section{ACKNOWLEDGEMENTS}

The authors would like to thank the Center for Research Support of the Sabin Laboratory for performing the measurements of $25(\mathrm{OH}) \mathrm{D}$ levels. 


\section{REFERENCES}

1. Shaw TE, Currie GP, Koudelka CW, Simpson EL. Eczema prevalence in the United States: data from the 2003 National Survey of Children's Health. J Invest Dermatol. 2011;131:67-73.

2. Boguniewicz M, Leung DY. Atopic dermatitis: a disease of altered skin barrier and immune dysregulation. Immunol Rev. 2011;242:233-46.

3. Russell M. Assessing the relationship between vitamin D3 and stratum corneum hydration for the treatment of xerotic skin. Nutrients. 2012;4:1213-8.

4. Holick MF. Vitamin D deficiency. N Engl J Med. 2007;357:266-81.

5. Benson AA, Toh JA, Vernon N, Jariwala SP. The role of vitamin $D$ in the immunopathogenesis of allergic skin diseases. Allergy. 2012;67:296-301.

6. Hewison M. Vitamin D and innate and adaptive immunity. Vitam Horm. 2011;86:23-62.

7. Gurlek A, Pittelkow MR, Kumar R. Modulation of growth factor/cytokine synthesis and signaling by 1 alpha,25-dihydroxy vitamin $\mathrm{D}(3)$ : implications in cell growth and differentiation. Endocr Rev. 2002;23:763-86.

8. Youssef DA, Miller CW, El-Abbassi AM, Cutchins DC, Cutchins C, Grant WB, et al. Antimicrobial implications of vitamin D. Dermatoendocrinol. 2011;3:220-9.

9. Hata TR, Kotol P, Jackson M, Nguyen M, Paik A, Udall D, et al. Administration of oral vitamin $D$ induces cathelicidin production in atopic individuals. J Allergy Clin Immunol. 2008;122:829-31.

10. Oren E, Banerji A, Camargo CA Jr. Vitamin D and atopic disorders in an obese population screened for vitamin D deficiency. J Allergy Clin Immunol. 2008;121:533-4.

11. Baïz N1, Dargent-Molina P, Wark JD, Souberbielle JC, Annesi-Maesano I; EDEN Mother-Child Cohort Study Group. Cord serum 25-hydroxyvitamin D and risk of early childhood transient wheezing and atopic dermatitis. J Allergy Clin Immunol. 2014;133:147-53.

12. Ehlayel MS, Bener A, Sabbah A. Is high prevalence of vitamin D deficiency evidence for asthma and allergy risks? Eur Ann Allergy Clin Immunol. 2011;43:81-8.

13. Solvoll K, Soyland E, Sandstad B, Drevon CA. Dietary habits among patients with atopic dermatitis. Eur J Clin Nutr. 2000;54:93-7.

14. Bäck O, Blomquist HK, Hernell O, Stenberg B. Does vitamin D intake during infancy promote the development of atopic allergy? Acta Derm Venereol. 2009;89:28-32.

15. Peroni DG, Piacentini GL, Cametti E, Chinellato I, Boner AL. Correlation between serum 25-hydroxyvitamin $\mathrm{D}$ levels and severity of atopic dermatitis in children. $\mathrm{Br}$ J Dermatol. 2011;164:1078-82.

16. Samochocki Z, Bogaczewicz J, Jeziorkowska R, Sysa-Jędrzejowska A, Glińska 0 , Karczmarewicz E, et al. Vitamin D effects in atopic dermatitis. J Am Acad Dermatol. 2013;69:238-44.

17. Chiu YE, Havens PL, Siegel DH, Ali O, Wang T, Holland KE, et al. Serum 25-hydroxyvitamin $D$ concentration does not correlate with atopic dermatitis severity. J Am Acad Dermatol. 2013;69:40-6.

18. Javanbakht MH, Keshavarz SA, Djalali M, Siassi F, Eshraghian MR, Firooz A, et al. Randomized controlled trial using vitamins $E$ and $D$ supplementation in atopic dermatitis. J Dermatolog Treat. 2011;22:144-50.

19. Amestejani M, Salehi BS, Vasigh M, Sobhkhiz A, Karami M, Alinia H, et al. Vitamin D supplementation in the treatment of atopic dermatitis: a clinical trial study. J Drugs Dermatol. 2012;11:327-30.

20. Holick MF, Binkley NC, Bischoff-Ferrari HA, Gordon CM, Hanley DA, Heaney RP, et al. Evaluation, treatment, and prevention of vitamin $D$ deficiency: an Endocrine Society clinical practice guideline. J Clin Endocrinol Metab. 2011;96:1911-30.

21. Wulf HC, Bech-Thomsen N. A UVB phototherapy protocol with very low dose increments as a treatment of atopic dermatitis. Photodermatol Photoimmunol Photomed. 1998;14:1-6.

22. Who.int [Internet]. World Health Organization, 2003. INTERSUN: the Global UV Project: a guide and compendium. [cited 2014 0ct 21]. Available from: http:// www.who.int/uv/publications/intersunguide/en/

23. Who.int [Internet]. World Health Organization World Meteorological Organization, United Nations Environment Programme and International Commission on NonIonizing Radiation Protection. Global Solar UV Index: A Practical Guide. 2002 [cited 2014 Jan 02]. Available from: http://www.who.int/uv/publications/globalindex/en/

24. Hanifin JM, Rajka G. Diagnostic features of atopic dermatitis. Acta Derm Venereol Suppl. 1980;92:44-7.

25. 25. Severity scoring of atopic dermatitis: the SCORAD index. Consensus Report of the European Task Force on Atopic Dermatitis. Dermatology. 1993;186:23-31.

26. 26 Weng FL, Shults J, Leonard MB, Stallings VA, Zemel BS. Risk factors for low serum 25-hydroxyvitamin $D$ concentrations in otherwise healthy children and adolescents. Am J Clin Nutr. 2007;86:150-8.
27. Peters BS, dos Santos LC, Fisberg M, Wood RJ, Martini LA. Prevalence of vitamin D insufficiency in Brazilian adolescents. Ann Nutr Metab. 2009;54:15-21.

28. Heaney RP, Abrams S, Dawson-Hughes B, Looker A, Marcus R, Matkovic V, et al. Peak bone mass. Osteoporos Int. 2000;11:985-1009.

29. Sedrani SH. Low 25-hydroxyvitamin D and normal serum calcium concentrations in Saudi Arabia: Riyadh region. Ann Nutr Metab. 1984;28:181-5.

30. Wjst $\mathrm{M}$, Dold $\mathrm{S}$. Genes, factor $\mathrm{X}$, and allergens: what causes allergic diseases? Allergy. 1999;54:757-9.

31. Gale CR, Robinson SM, Harvey NC, Javaid MK, Jiang B, Martyn CN, et al. Maternal vitamin $\mathrm{D}$ status during pregnancy and child outcomes. Eur J Clin Nutr. 2008;62:68-77.

32. Hata TR, Audish D, Kotol P, Coda A, Kabigting F, Miller J, et al. A randomized controlled double-blind investigation of the effects of vitamin D dietary supplementation in subjects with atopic dermatitis. J Eur Acad Dermatol Venereol. 2014;28:781-9.

33. Laske N, Niggemann B. Does the severity of atopic dermatitis correlate with serum IgE levels? Pediatr Allergy Immunol. 2004;15:86-8.

34. Castro LC. The vitamin D endocrine system. Arq Bras Endocrinol Metabol. 2011;55:566-75.

35. Vähävihu K, Ylianttila L, Salmelin R, Lamberg-Allardt C, Viljakainen H, Tuohimaa $\mathrm{P}$,et al. Heliotherapy improves vitamin $\mathrm{D}$ balance and atopic dermatitis. $\mathrm{Br} \mathrm{J}$ Dermatol. 2008;158:1323-8

36. Juzeniene A, Moan J. Beneficial effects of UV radiation other than via vitamin D production. Dermatoendocrinol. 2012;4:109-17.

37. Autio P, Komulainen P, Larni HM. Heliotherapy in atopic dermatitis: a prospective study on climatotherapy using the SCORAD index. Acta Derm Venereol. 2002;82:436-40.

38. Silverberg Jl, Hanifin J, Simpson EL. Climatic factors are associated with childhood eczema prevalence in the United States. J Invest Dermatol. 2013;133:1752-9.

39. Taksler GB, Cutler DM, Giovannucci E, Smith MR, Keating NL. Ultraviolet index and racial differences in prostate cancer incidence and mortality. Cancer. 2013;119:3195-203.

40. Silverberg Jl, Braunstein M, Lee-Wong M. Association between climate factors pollen counts, and childhood hay fever prevalence in the United States. J Allergy Clin Immunol. 2015;135:463-9

41. Harari M, Shani J, Seidl V, Hristakieva E. Climatotherapy of atopic dermatitis at the Dead Sea: demographic evaluation and cost-effectiveness. Int J Dermatol. 2000;39:59-69.

42. Holick MF. Vitamin D status: measurement, interpretation and clinical application. Ann Epidemiol. 2009;19:73-8.

43. Ovesen L, Andersen R, Jakobsen J. Geographical differences in vitamin D status, with particular reference to European countries. Proc Proc Nutr Soc 2003;62:813-21.

MAILING ADDRESS:

Kleyton de Carvalho Mesquita

SGAN 605, Avenida L2 Norte.

70840 - 901 - Brasília - DF

Brazil

E-mail: kleyton.mesquita@gmail.com

How to cite this article: Mesquita K de C, Igreja ACSM, Costa IM. Ultraviolet index: a light in atopic dermatitis and vitamin D research? An Bras Dermatol. 2016;91(1):34-9. 